\title{
Evidence for pore water composition controlling carbonate morphology in concrete and the further effect of gamma
} radiation

DOI:

10.1016/j.conbuildmat.2020.122049

\section{Document Version}

Accepted author manuscript

Link to publication record in Manchester Research Explorer

Citation for published version (APA):

Potts, A., \& Leay, L. (2021). Evidence for pore water composition controlling carbonate morphology in concrete and the further effect of gamma radiation. Construction and Building Materials, 275, [122049].

https://doi.org/10.1016/j.conbuildmat.2020.122049

\section{Published in:}

Construction and Building Materials

\section{Citing this paper}

Please note that where the full-text provided on Manchester Research Explorer is the Author Accepted Manuscript or Proof version this may differ from the final Published version. If citing, it is advised that you check and use the publisher's definitive version.

\section{General rights}

Copyright and moral rights for the publications made accessible in the Research Explorer are retained by the authors and/or other copyright owners and it is a condition of accessing publications that users recognise and abide by the legal requirements associated with these rights.

\section{Takedown policy}

If you believe that this document breaches copyright please refer to the University of Manchester's Takedown Procedures [http://man.ac.uk/04Y6Bo] or contact uml.scholarlycommunications@manchester.ac.uk providing relevant details, so we can investigate your claim.

\section{OPEN ACCESS}




\title{
Evidence for Pore Water Composition Controlling Carbonate Morphology in Concrete and the Further Effect of Gamma Radiation
}

\author{
A. Potts ${ }^{\mathrm{a}, \mathrm{b}, 1, *}$, L. Leay ${ }^{\mathrm{a}, \mathrm{c}}$ \\ ${ }^{a}$ Dalton Cumbrian Facility, The University of Manchester, U.K. \\ ${ }^{b}$ The Department of Chemistry, The University of Manchester, U.K. \\ ${ }^{c}$ The Department of Mechanical, Aerospace and Civil Engineering, The University of \\ Manchester, U.K.
}

\begin{abstract}
$\underline{\text { Radiation, heat and carbonation can all affect the performance of concrete }}$ structures. This study applies either a $1.5 \mathrm{MGy}$ gamma radiation dose or thermal treatment at $60^{\circ} \mathrm{C}$, followed by an accelerated carbonation period. $\underline{\text { In comparison to a control sample, irradiation and heat treatment lead to an }}$ $\underline{\text { increase in the carbonation depth which correlates with an increase in crack }}$ depth induced by restrained drying-induced shrinkage. When compared to thermally treated samples, there is greater variability in the crack depth of irradiated samples which we ascribe to a radiation-induced change in the $\underline{\text { mechanical properties of the cement paste. X-ray diffraction is used to iden- }}$ tify the calcium carbonate polymorphs that form as result of carbonation. The dominant phase in the control sample is vaterite whereas the dominant phase in both the irradiated and thermally treated samples is calcite. Gamma
\end{abstract}

\footnotetext{
*Corresponding author

Email address: alexander.potts@uknnl.com (A. Potts)

${ }^{1}$ Present address: The National Nuclear Laboratory, U.K.
} 
irradiation leads to a greater calcite:vaterite ratio than thermal treatment. The sequential application of gamma radiation/heat treatment followed by a carbonation period rules out radiolytically produced calcium peroxide octahydrate as the cause of the polymorph switch as it is too short-lived. A new mechanism is hypothesised, where elemental substitution into the calcium carbonate lattice results in deformation and so alters the morphology of the calcium carbonate, leading to the formation of a different polymorph. Keywords: Gamma Radiation, Accelerated Carbonation, Cement, Concrete, Nuclear

\section{Motivation}

Cement and concrete are widely used in the nuclear industry for a variety of purposes, with structural uses being very common. A key consideration for structural uses is the long operational timespan, typically on the order of decades, where they are exposed to multiple degradation pathways, such as radiation, erosion and thermal dehydration. Since these structures provide safety functions [1] it is important to understand how these structures age. Carbonation, the process of $\mathrm{CO}_{2}$ gas from the atmosphere reacting with calcium containing phases present in cement [2], can occur over these long operational timescales. The effects of carbonation are well documented, including changes in porosity, cracking and pH [3]. Carbonation is normally $\underline{\text { associated with an increase in compressive strength }[4,5] \text {, however it has }}$ been shown to decrease the compressive strength in some situations [6]. The drop in $\mathrm{pH}$ can lead to the corrosion of steel re-bar, which is sometimes present in structural concrete, and consequently lead to cracking in the con- 
crete structure and spalling in some cases $[3,7,8]$. Studies have shown that irradiation can modify the carbonation process, leading to a different calcium carbonate polymorph being formed due to thermal dehydration, as well as an increase in the total amount of carbonated phase $[9,10]$. The modifying effects of radiation on carbonation, and hence on compressive strength, are not yet fully understood and, since various studies have used cement of specific compositions $[9,10,11]$, appear to be affected by the composition of the cement.

It has long been reported that radiation affects the properties of cement and concrete structures [12] and that changes in compressive strength as a result of irradiation depend on the composition of the cement. While many studies have focused on the combined effect of neutron and gamma irradiation, applicable to nuclear power plants, there are only a few studies on the effect of gamma radiation alone, which is relevant to facilities that store nuclear materials. A dose of $5 \times 10^{5}$ Gy has been shown to cause a $10 \%$ drop in the compressive strength of ordinary Portland cements (OPC) cements $[13,14]$, with a larger change observed when a lower dose rate was applied [14]. Whilst gamma radiation typically causes the compressive strength to decrease, carbonation normally results in an increase [2]. In the case of early aged blast furnace slag (BFS) blended cements, Mobasher et al. [15] found that compressive strength increased after irradiation, accompanied by increased porosity. Craeye et al. [16] found that compressive strength was reduced when samples were exposed to gamma radiation at an early age, with the addition of BFS increasing this behaviour. Tajuelo Rodriguez et al. [17] examined synthesised calcium-silicate-hydrate samples subjected up to 
0.784 MGy over 12 months, and found little change in the chemical-physio properties of the material. Interestingly, no interlayer water was lost which is believed to be the main reason for lack of change in the mechanical properties. There have been several studies measuring the radiolytic production of $\mathrm{H}_{2}$ in cementitious systems, which have highlighted radiolytic processes can be affected by numerous variables, such as water content, phases present and dose rate. $[18,19,20]$

When simultaneously exposed to gamma radiation and a carbonating atmosphere, the degree of carbonation in a hardened cement paste increases $[10,11]$. All of the studies that have examined the effects of carbonation and gamma irradiation have been conducted under natural carbonation conditions, resulting in experiments several months long.

Vodák et al. [10] found that irradiation resulted in a decrease in the mass of cement paste, and suggested that this mass loss was due to dehydration caused by radiolytic breakdown of the pore water. Bouniol and Bjergbakke [21] found that unstable calcium octahydrate peroxide can be formed in the cement pore water during irradiation, however, in the case of very low dose rates there needs to be a minimum amount of hydrogen peroxide present in solution before the calcium octahydrate peroxide can form. Higher dose rates were shown to increase the maximum amount of the peroxide formed. It has been suggested that this unstable calcium peroxide can lead to increased carbonation in a radiation field [9, 13]. Maruyama et al. [9] reported that samples simultaneously exposed to gamma radiation and carbonation formed vaterite and aragonite predominantly, whereas calcite was dominant under solely carbonating atmospheres. Vaterite, aragonite and calcite are 
metastable polymorphs of calcium carbonate $\left(\mathrm{CaCO}_{3}\right)$, that possess different morphologies, [22, 23, 24, 25, 26].

In carbonation experiments, it is common to use accelerated testing, where the volume of $\mathrm{CO}_{2}$ in the air around the sample is increased. The maximum amount of $\mathrm{CO}_{2}$ which is representative of natural carbonation is still debated. For OPC, Castellote et al. [27] showed that $3 \% \mathrm{CO}_{2}$ atmosphere produced microstructure similar to natural carbonation, whereas at $10 \% \mathrm{CO}_{2}$ there were obvious differences, such as the disappearance of the C-S-H gel. Auroy et al. [28] also demonstrated that $3 \% \mathrm{CO}_{2}$ was representative of natural carbonation for pure OPC systems. When the cement system contained both BFS and fly ash (FA) there was a larger discrepancy between accelerated and natural carbonation results. Furthermore, Auroy et al. [28] found that different phases present in hardened cement pastes (HCP) result in different carbonation polymorphs.

Calcium carbonate polymorphs are well researched in other fields, in particular their precipitation in seawater conditions. It is well established that pure calcite is the most stable polymorph and vaterite is the least stable [22] due to the crystal structures of the polymorph, however the inclusions of various ions can affect the stability. For example, $\mathrm{Mg}$ can substitute into the calcite lattice, destabilising the structure with the inclusion of more $\operatorname{Mg}[23,24]$. As a result of this destabilisation, aragonite becomes more favourable. Similarly Bots et al. [23] found that S can substitute into calcite (as $\mathrm{SO}_{4}$ ) and replace $\mathrm{CO}_{3}$, causing an anisotropic change in the unit cell parameters. However, S substitution did not significantly affect the crystal cell parameters of aragonite or vaterite, meaning these polymorphs were 
more apparent when $\mathrm{S}$ was present during synthesis. Being the least stable polymorph, Rodriguez-Blanco et al. [25] demonstrated that vaterite can transform to calcite under ambient conditions, resulting in a defected calcite morphology. Both $\mathrm{pH}$ and the presence of $\mathrm{Mg}$ have been shown to alter the pathway to forming calcite, where neutral $\mathrm{pH}$ or the presence of $\mathrm{Mg}$ led to the formation of calcite directly from amorphous calcium carbonate [26]. Hsiao et al. [29] have examined the effects of $\mathrm{Ar}^{+}$ion irradiation on calcite, showing an insensitivity to radiation, via both experimental and modelling methods. Whilst gamma radiation is significantly different to ion irradiation [30, 31], Hsiao et al. [29] findings would imply that radiation damage directly to the calcite phase would not affect the type of polymorph. Therefore, an indirect effect of irradiation is more likely to be the cause of the polymorph switch. Carbonation alters the porosity of cementitious materials and directly influences the compressive strength of the material. The different carbonate polymorphs have different molar volumes, which leads to different degrees of porosity and so may alter the compressive strength accordingly. This paper seeks to better understand the mechanism that leads to a given calcium carbonate polymorph being formed as a result of gamma irradiation alongside carbonation, utilising a new methodology. The literature has shown that thermal dehydration affects the carbonate polymorph formed [9] and so this paper investigates dehydration and any associated cracking so that the extent of $\mathrm{CO}_{2}$ penetration into the cement, and associated depth of carbonation, can be understood. 


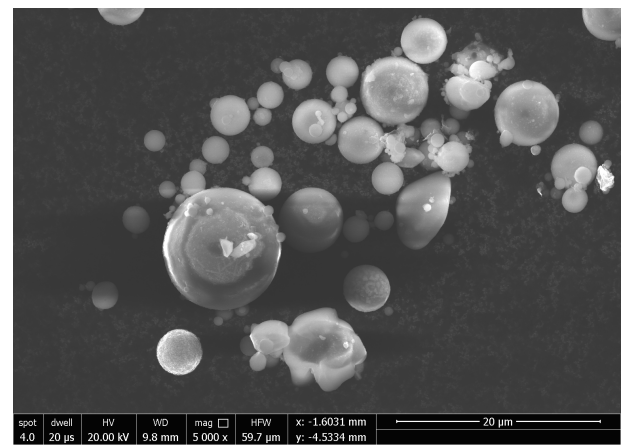

(a) FA

\section{Methodology}

\subsection{Sample Preparation} Figure 1 and Table 1.

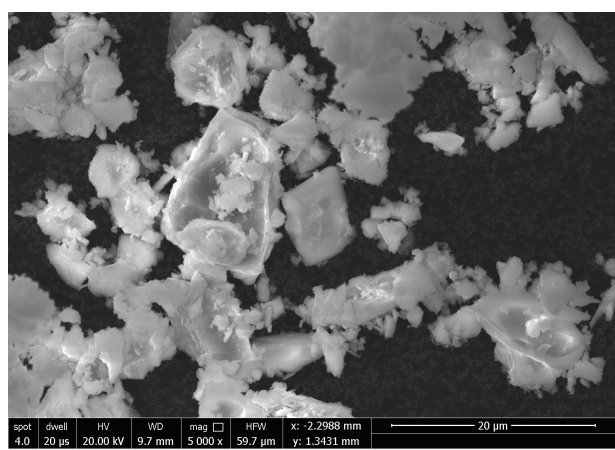

(b) OPC

Figure 1: SEM images taken of the FA and OPC powders, using a secondary electron detector

The composition of our samples is based on a specification provided by Sellafield Ltd (equivalent to BS EN 197-1 CEM I 42,5N [32]). Ordinary Portland cement (OPC) was used to meet Sellafield Ltd specification and fly-ash (FA), category EN450-NB from Drax [33], was used. A mix ratio of 3:2 OPC:FA was used with a water to solids ratio of 0.5. Characterisation of the raw powders was carried out via SEM and EDS which are provided in

The above constituents were combined in planetary mixer for 5 minutes and the resultant paste was then decanted into $40 \mathrm{~mm}$ cubic moulds, covered with clingfilm and left overnight. After removing from the moulds, samples were placed into a water bath filled with a lime saturated solution to cure for 6 weeks. The temperature was set to $20^{\circ} \mathrm{C}$ which fluctuated by approximately 
Table 1: Averaged EDS results for the elemental composition of the FA and OPC powders. 30 measurements were taken for each powder. Values provided are wt $\%$

\begin{tabular}{l|cccc}
\hline & $\mathrm{O}$ & $\mathrm{Al}$ & $\mathrm{Si}$ & $\mathrm{K}$ \\
\hline $\mathrm{FA}$ & $51.3 \pm 6.3$ & $11.9 \pm 4.6$ & $22.5 \pm 8.0$ & $2.3 \pm 1.2$ \\
OPC & $32.67 \pm 13.6$ & $2.1 \pm 2.8$ & $7.5 \pm 3.9$ & - \\
\hline & $\mathrm{Fe}$ & $\mathrm{Ca}$ & $\mathrm{Cu}$ & $\mathrm{Mg}$ \\
\hline $\mathrm{FA}$ & $6.1 \pm 11.5$ & - & - & - \\
OPC & $4.2 \pm 6.3$ & $49.9 \pm 13.3$ & $0.5 \pm 0.3$ & $0.50 \pm 0.31$ \\
\hline
\end{tabular}

$2^{\circ} \mathrm{C}$ over this period. In total, 9 samples were produced from this mixture. As a result the samples were 42 days old a the start of the experiment.

\subsection{Irradiation and Heat Treatment}

After being removed from the water bath the samples were patted dry and left on a bench top for an hour to remove any excess moisture. 5 faces of the samples were coated with self-adhesive aluminium tape to restrict carbonation to 1 direction. The masses were recorded before and after applying the aluminium tape.

Irradiation was carried out at the Dalton Cumbrian Facility [34] using a self shielded ${ }^{60} \mathrm{Co}$ gamma irradiator. The exposed face of 3 samples was placed so it was closest to the radiation source. The irradiation lasted 65.5 hours, with a dose rate of $385 \mathrm{~Gy} / \mathrm{min}$, giving a total dose of $1.5 \mathrm{MGy}$. The samples were stacked on top of each other, meaning each received a slightly different dose. This variation is within $5 \%$.

Due to the lead shielding surrounding the sample chamber of the gamma irradiator [34], the temperature rises during the irradiation, reaching approx- 
imately $60^{\circ} \mathrm{C}$. To distinguish the effects of gamma irradiation from heating, 3 samples were placed into a oven set at $60^{\circ} \mathrm{C}$ during the irradiation. Additionally, 3 control samples were set aside in the lab during this time. This elevated temperature means some cracking was expected due to restrained drying shrinkage $[35,36]$. It should be noted that all the samples were exposed to atmospheric conditions during this period. Immediately after this treatment period, the mass of each sample was recorded before being placed into a carbonation chamber. Images were also taken of the exposed face, using a DSLR camera.

\subsection{Carbonation}

A simple carbonation chamber was constructed for this study, with a schematic given below in Figure 2. A feedback loop utilising a solenoid valve connected to a gas bottle is used to provide a $5 \% \mathrm{CO}_{2}$ atmosphere over the two week carbonation period. The $\mathrm{CO}_{2}$ level dropped to $4.3 \%$ over the final 10 hours as the supply from the gas bottle was depleted.

A K-33 BLG $\mathrm{CO}_{2}$ Sensor was used to detect the carbon dioxide level, as well as recording relative humidity and temperature. A saturated salts solution of sodium nitrite provided a relative humidity of around $75 \%$, higher than the expected $67 \%$ selected to maximise the accelerated carbonation process [37]. A final mass reading was taken as soon as the samples were removed from the carbonation chamber. Similarly, more images were taken of the exposed face so that the evolution of the cracks could be characterised. 


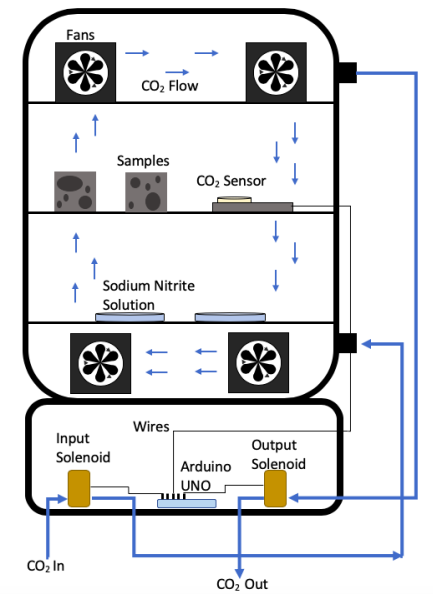

Figure 2: Schematic of the carbonation chamber built for this study

\subsection{Analysis}

Samples were sliced up for analysis, as Figure 3 demonstrates. The 2 slices from the top half were used for analysis via $\mathrm{pH}$ indicator spraying, XRD mapping techniques, and SEM (discussed in Section's 2.4.2- 2.4.4). The bottom half of each sample was cut into slices perpendicular to the exposed face. RS pro vernier calipers were used to keep the slice size consistent at $3 \mathrm{~mm}$. These slices were ground with an agate mortar and pestle and sieved to between $300-500 \mu \mathrm{m}$. Samples were stored in sealed plastic bags until analysis, with the time between grinding to a powder and being analysed kept to a minimum, ready for leaching of pore water and subsequent analysis of the leachate by ICP-AES.

\subsubsection{Characterisation of Cracking}

The obtained images of the exposed face were loaded into imaging software, whereby they were converted to 8-bit greyscale images. These were then manually thresholded using the histogram to highlight the cracking. A 


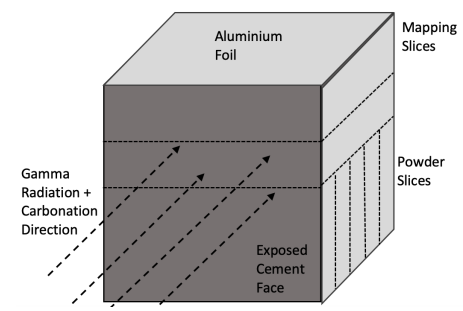

Figure 3: Schematic of the method used to slice samples for analysis. Mapping slices indicates slices used for the mapping XRD, phenophthalein indicator and SEM, whereas powder slices were the slices used for ICP-AES analysis.

distance calibration allowed a $30 \mathrm{~mm}$ square crop of the central section to be taken, avoiding any aluminium tape on the edges which would interfere with the subsequent analysis. This crop was then converted to a binary image and noise was manually cleaned up using a circular selection and fill tool. Speckling on the surface prevented automatic noise reduction software from working, due to the speckles overlapping with the cracks on the histogram during the thresholding process. In the case of the heated samples after treatment phase, this approach was significantly better than the automatic noise reduction, however, still resulted in cracks that look wider than they are. Supplementary material are provided, which show the process as 3 steps for the all the samples in Figure 5.

\subsubsection{Phenolphthalein Indicator}

With the mapping slices, phenolphthalein indicator was sprayed onto one side of a mapping slice. Digital image correlation was used to obtain multiple readings of the carbonation depth. Pictures were taken with a Nikon D3100 under ambient lighting, with the length of the sample obtained via vernier calipers for image calibration. Image $\mathrm{J}$ was used for the analysis, with a 
script provided by Prof. Helmut Glünder, allowing a measurement to be taken every 10 pixels over a manually set range for each sample. The colour change from the phenolphthalein indicator was used as a guide when cutting the sample into edge and centre pieces for further analysis: centre pieces did not exhibit a colour change and so were considered to be uncarbonated. This approach allowed comparison of carbonated material to uncarbonated material and so negates the need to analyse samples after treatment but before carbonation.

\subsubsection{Mapping XRD}

The mapping XRD scans were carried out from $16-60^{\circ} 2 \theta$ range, using a $0.116^{\circ} 2 \theta$ step size. Due to low counting rates each scan took 3 hours. Scans were taken from the exposed edge inwards, with $0.42 \mathrm{~mm}$ increments taken over a range of $12 \mathrm{~mm}$ for the heat treated and irradiated samples and $9 \mathrm{~mm}$ for the control samples. These ranges were guided by the carbonation depths determined by the phenolphthalein indicator. For each sample, total run time was approximately 90 hours. A custom 3D printed cell made by Dr. J. Warren (Senior Experimental Officer, University of Manchester), was used to flow nitrogen over the sample throughout the run, preventing carbonation.

\subsubsection{Scanning Electron Microscope}

A Scanning Electron Microscope (SEM) was used to examine the morphology of carbonation products. A slice of sample was polished using successive grits up to 2000 grit paper, for 2 minutes each time.

After polishing the sample was rinsed and dried overnight at $30^{\circ} \mathrm{C}$ under vacuum. After drying the sample was gold coated for 15 seconds to avoid the 
sample charging.

\subsubsection{Analysis of Powdered Samples}

To understand the pore water chemistry, slices taken from the edge and middle of each carbonated sample, which were subsequently powdered, were placed in vials with de-ionised water $(18.2 \mathrm{M} \Omega)$ in a 1:10 mass ratio, capped, and stored for 28 days at room temperature. The leachate was then sampled and passed through a $0.45 \mu \mathrm{m}$ filter prior to analysis via inductively coupled plasma atomic emission spectroscopy (ICP-AES).

\section{Results}

\subsection{Extent of Carbonation}

Prior to carbonation, mass loss was observed in both the heat treated and irradiated samples, as shown in Figure 4. Since the degree of mass loss was within error between the irradiated and heated samples, evaporation of loosely bound pore water is thought to be the cause of this. Both the heated and irradiated samples gained significant mass after the carbonation stage compared to the control sample. Given that calcite is denser than the C-S-H phase, some of this mass gain could be from carbonation and, given the relative humidity in the carbonation chamber, some could be from re-adsorption of water.

The evaporation of water occurs from the exposed surface of the sample during the treatment phase, effectively drying out the exposed face. This has led to restrained drying shrinkage-induced cracking [35, 36], shown in

Figure 5. Cracking only occurs where strain is introduced and the extent of 


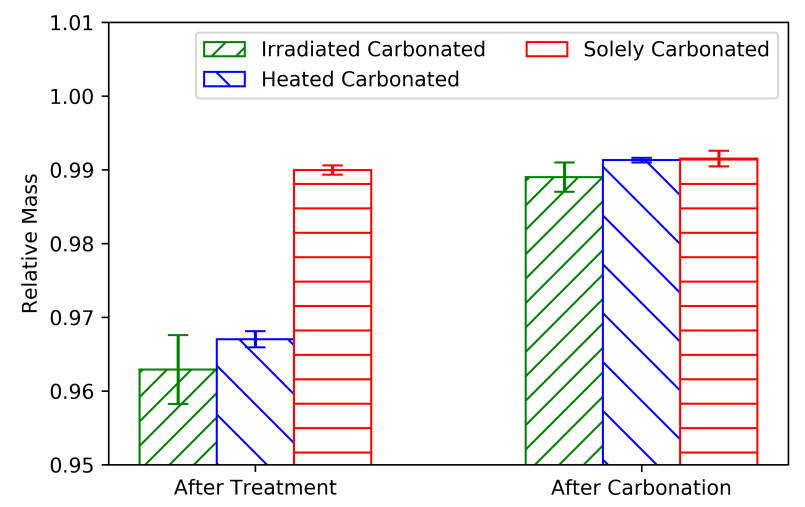

Figure 4: Mass measurements at each stage of the experiment. Each bar is an average of 3 samples

this process is affected by several factors, such as relative humidity, temperature and drying extent. Our results demonstrated a more developed crack network in the irradiated samples compared to the heat control samples. Greater cracking should lead to more penetration of $\mathrm{CO}_{2}$ and so increase the carbonation depth.

Carbonation depths were obtained from cement samples sprayed with phenolphthalein solution. As the ingress of the carbonation phase was not completely even, histograms are the best representation of these data sets. These are shown in Figure 6, where both the histogram and a kernel density estimation (KDE) are plotted.

As expected from the mass loss data in Figure 4 and the cracking observed in Figure 5, both the irradiated and heated samples show an increase in the carbonation depth. The mean values are provided in Table 2 , which demonstrates that heating or irradiating samples prior to carbonation effectively 


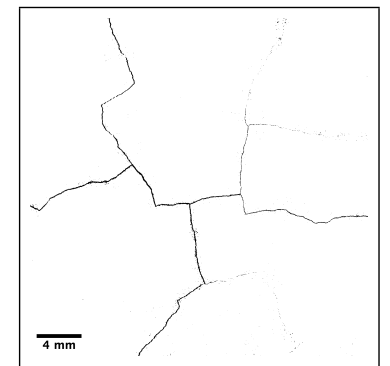

(a) Irradiated sample after treatment phase

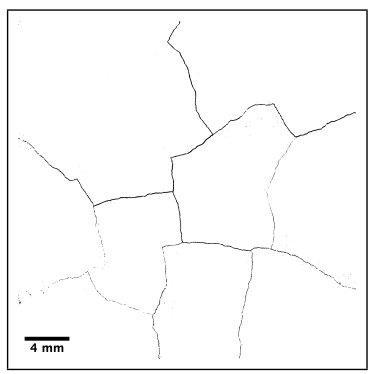

(d) Irradiated sample after carbonation phase

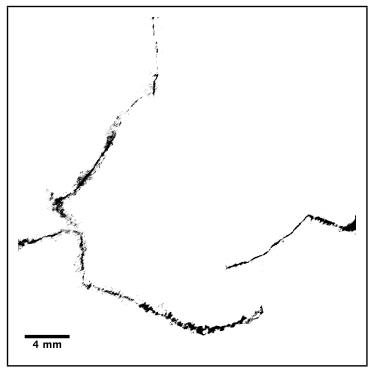

(b) Heated sample after treatment phase

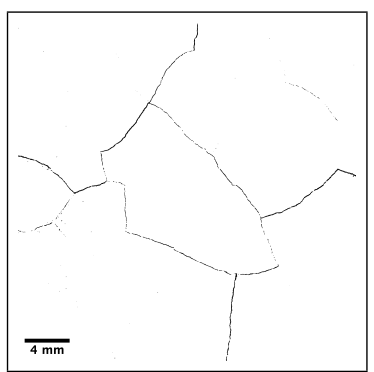

(e) Heated sample after carbonation phase

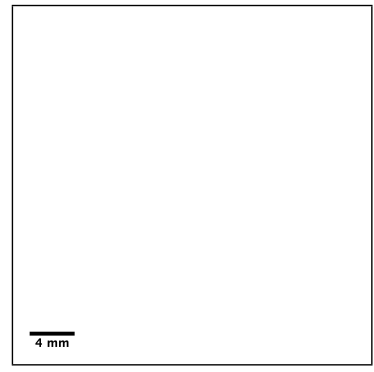

(c) Control sample after treatment phase

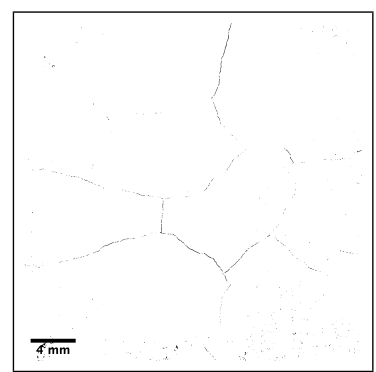

(f) Control sample after carbonation phase

Figure 5: Examples of the crack analysis. Note the darker, wider cracking observed on $5 \mathrm{~b}$ is an artefact of the noise reduction due to speckled sample surface. Cracking was not observed on the control sample after the treatment phase.

doubled the depth of carbonation ingress. Both Figure 6 and Table 2 show that the irradiated sample had a significantly wider spread of carbonation depth compared to the other sample groups. Figure 7 shows that cracks line up with indents in the phenolphthalein and we surmise that, since cracks would increase the diffusion of $\mathrm{CO}_{2}$ into the cement, the variation in carbonation depths correlates with various crack depths 


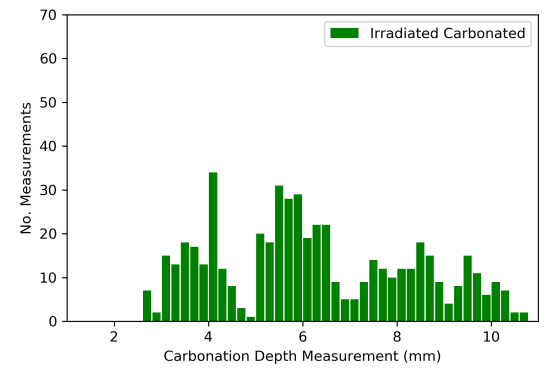

(a) Irradiated

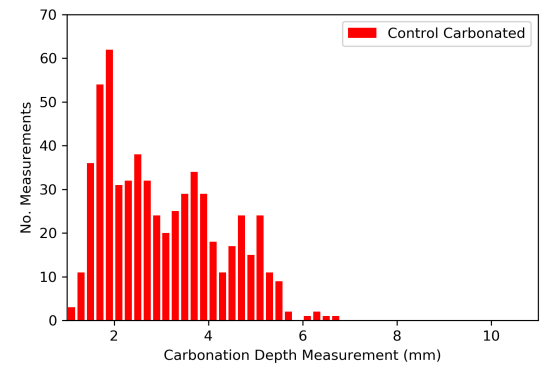

(c) Control

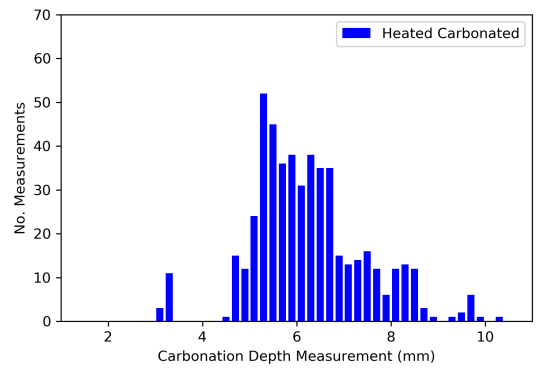

(b) Heat Control

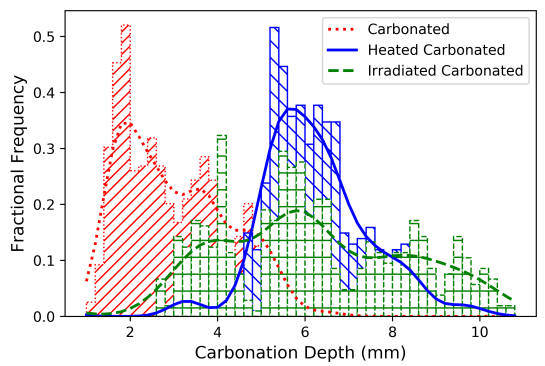

(d) KDE Plot

Figure 6: Histograms of the carbonation depth measurements obtained in Image J. Kernel density estimation (lines in Figure 6d) plots are to guide the eye.

Table 2: Mean distances from the carbonation depth measurements.

\begin{tabular}{lcc}
\hline Sample & Mean $(\mathrm{mm})$ & Deviation $(\mathrm{mm})$ \\
\hline Irradiated Carbonated & 6.14 & 2.24 \\
Heated carbonated & 6.18 & 1.35 \\
Carbonated & 3.02 & 1.24 \\
\hline
\end{tabular}

\subsection{Carbonation Phases}

The XRD data are provided in Figure 8 using heatmaps to clearly present the multiple XRD spectra that were collected at intervals along sliced sam- 


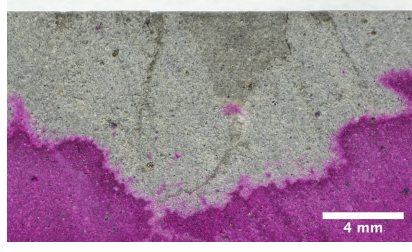

(a) Irradiated

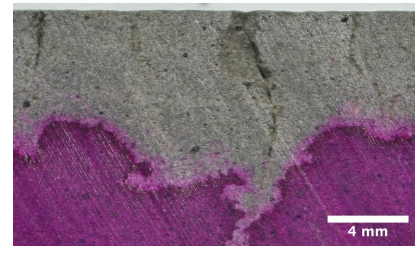

(b) Heat Control

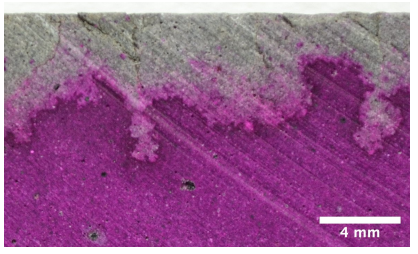

(c) Control

Figure 7: Images of slices sprayed with phenolphthalein showing the extent of cracking in the carbonated regions.

ples. Figure 8a shows the dominant carbonation polymorph formed in the control sample to be vaterite, with no appreciable proportion of calcite observed. Both the irradiated and heat treated samples also show vaterite formation, however, calcite is also formed in considerable quantities. The observed quartz in Figure 8 is due to the fly-ash.

There are subtle differences between the heatmaps generated for the irradiated and heat treated samples; the calcite:vaterite ratio is significantly larger in the irradiated sample, compared to the heat treated sample. These ratios are provided in Figure 9, which compares the area of the vaterite peak at $27.12 \theta$ to the area of the calcite peak at $29.42 \theta$.

\subsection{Pore Water Chemistry and SEM imaging of carbonate morphology}

Figure 10 shows an example of the carbonation products found in the irradiated sample. Energy dispersive x-ray spectroscopy was used to identify phases with substantial carbon content, typical of carbonation products. Figure 10 is believed to be calcite as the morphology appears to be somewhat cubic rather than the spherical morphology of vaterite. The morphology of the calcite is imperfect compared to the cubic morphology observed when calcium carbonate is synthesised from solution [22]. Imperfect morphology 


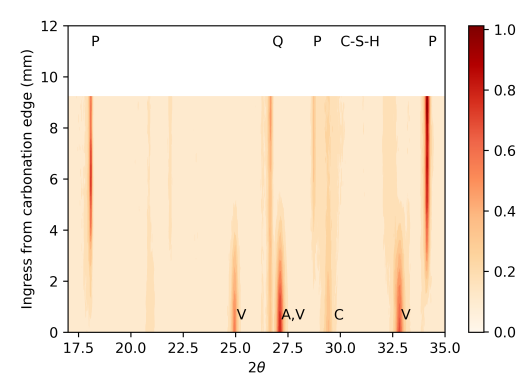

(a) Control

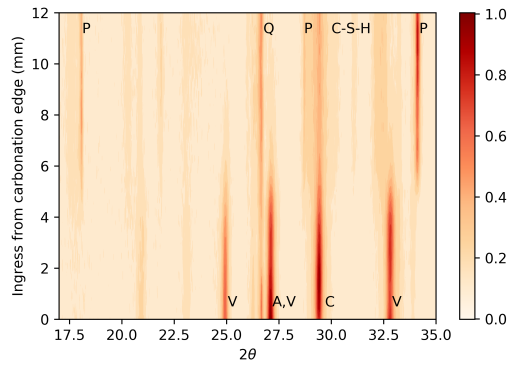

(b) Heat treated

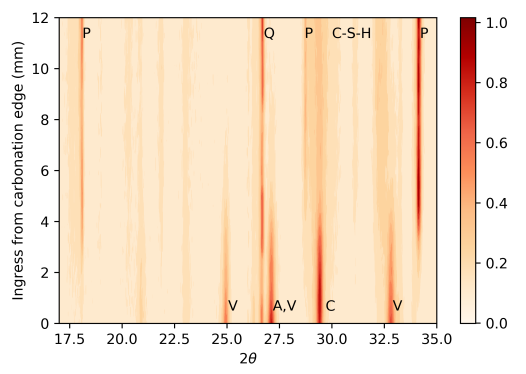

(c) Irradiated

Figure 8: Heatmaps showing evolution of the carbonation phase into the sample, where the bottom is the carbonated edge. $\mathrm{P}$ = portlandite, $\mathrm{Q}=$ quartz, $\mathrm{V}=$ vaterite, $\mathrm{A}=$ aragonite, $\mathrm{C}=$ calcite, $\mathrm{C}-\mathrm{S}-\mathrm{H}=$ calcium-silicate-hydrate

indicates the material structure is defected, which could be caused by elements from the cement matrix interacting with the carbonate. Analysis of the pore water leachate provides further insight into this by identifying elements present in the edge and middle of the samples.

Figure 11 shows some interesting trends, in particular for the elements $\mathrm{Ca}, \mathrm{Na}, \mathrm{K}$ and $\mathrm{S}$. Here, leachate taken from the middle of the samples corresponds to uncarbonated cement while samples from the edge were found to be carbonated. The data for $\mathrm{Si}$ and Mg suggests that they appear in the pore water only in small concentrations and do not seem to be affected by 


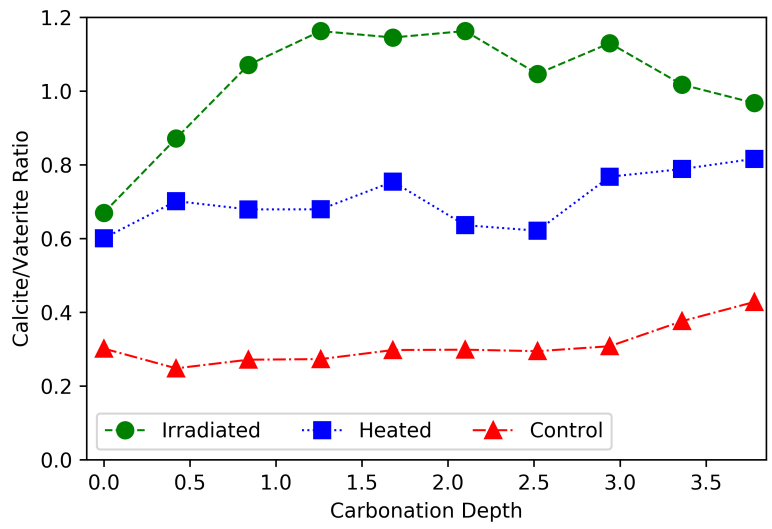

Figure 9: Plot comparing the calcite to vaterite ratio from Figure 8

carbonation, heat treatment or irradiation.

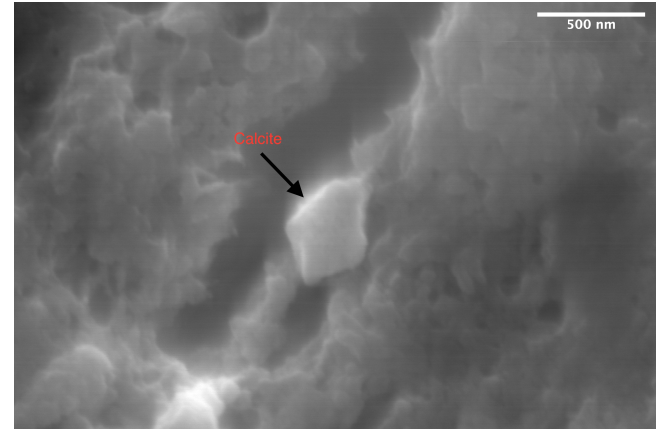

Figure 10: SEM image of the carbonated area of the irradiated sample, showing what is thought to be a calcite crystal, as determined by EDX

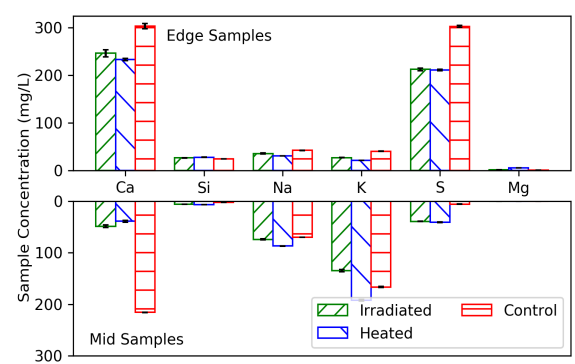

Figure 11: ICP-AES data for leachate taken from the edge and middle of the different samples. Error bars are the standard deviation from 3 repeats of same leachate

Leachate collected from the middle of the irradiated and heat treated samples has a lower Ca concentration when compared to the control samples suggesting that irradiation and heating prior to carbonation lead to the formation of Ca-bearing mineral phases. Examining the leachate from all 3 edge 
samples shows an increase in the Ca content, meaning that some Ca-bearing phases have dissolved during the carbonation period. Irradiation/heating appear to increase this effect given the larger relative increase in Ca content from centre to edge. A decrease is observed in the $\mathrm{Na}$ and $\mathrm{K}$ content of the leachate from the edge samples compared to the centre samples, indicating these ions may have been incorporated into the carbonate phase at the expense of $\mathrm{Ca}$, which would also contribute to the increase in Ca content at the edges.

Gamma irradiation and/or heating has resulted in an increase in the concentration of $\mathrm{S}$ in the leachate from the middle of the samples, suggesting that it was released into solution prior to carbonation. This suggests that both irradiation and heating leads to dissolution of S-containing phases prior to carbonation. Data collected from leachate from the edge of the samples shows that the concentration of $\mathrm{S}$ in the pore water increases in all three samples compared to the middle; this is due to the carbonation of ettringite $[28,38,39]$.

\section{Discussion}

\subsection{Carbonation Depth}

The data provided in Section 3.1 is in good agreement with Vodák et al. [10] and Bar-Nes et al. [11]: irradiation led to an increase in the carbonation depth. In our samples, the mean carbonation depth in the control sample was $3.02 \mathrm{~mm}$ compared to $6.18 \mathrm{~mm}$ in the irradiated samples. Thermal dehy$\underline{\text { dration, indicated by mass loss of } 3.71 \pm 0.47 \% \text { and } 3.30 \pm 0.11 \% \text { after the }}$ treatment phase for both the irradiated and heat treated samples respectively 
(Figure 4), allowed $\mathrm{CO}_{2}$ to diffuse in to the cement. This $\mathrm{CO}_{2}$ diffusion was further enhanced by the appearance of cracks, in both the irradiated and heat treated samples after the treatment phase (Figure 5). Similar mass loss observed between the irradiated and heated samples after treatment indicates a similar amount of pore water removal in these samples. The $2.51-2.71 \%$ mass increase after carbonation for the irradiated and heat treated samples is due to either the carbonation process or water re-absorbing into the samples.Future work could identify the cause by re-running the experiment, but instead exposing the samples to normal atmosphere at the same relative humidity as the carbonation run. Thermogravimetric analysis could then be used to quantify the phase contents.

The more extensive cracking seen on the exposed face of irradiated samples (Figure 5) warrants further consideration. Since cracking is a response to strain brought about by shrinkage of the material $[35,36]$, the more extensive cracking indicates that irradiation has altered the mechanical properties of the cement matrix. On the microscale, cement is heterogeneous and this may lead to different radiation responses in different areas of the microstructure. The pore network usually consists of micro, meso and macropores (as defined by IUPAC) [40] which are filled with water and may not be interconnected: radiolysis of water in smaller pores leads to an increase in hydrogen production with an associated modification of the radiation chemistry [41, 42]. Cement also contains gel water which can be thought of as water between layers of C-S-H: Ca in the interlayer space can act as an electron trap, evidenced by enhanced radiolysis of the interlayer water [19]. Under irradiation, energy absorbed by a solid phase can be transferred to surface water and this 
energy transfer is influenced by the chemistry of the solid [43]. More generally, irradiation of polymers is known to cause either cross-linking or chain scission (depending on the nature of the chemical bonds) which can affect mechanical properties $[44,45,46]$. Neutron irradiation has been shown to change the stored energy in many different materials [47], meaning it may be a possibility for a cementitious system. We can envisage a scenario where chemical bonds in the C-S-H are affected by irradiation but the exact response depends on local chemistry and local porosity. Differing amounts of strain may be responsible for the different crack patterns seen in Figure 5, and affect the crack depth seen in Figure 7.

\subsection{Comparison to Carbonation Mechanisms Proposed in Other Studies}

The formation of calcite in the irradiated samples contrasts with the results of Maruyama et al. [9] which found that irradiation induced the formation of vaterite and aragonite. The difference between the resultant polymorphs in our study and Maruyama et al. [9] is believed to be due to our study utilising FA blended cements, whereas Maruyama et al. [9] used solely OPC cements. Both our study and that of Maruyama et al. [9] showed that irradiation results in the formation of a different polymorph compared to carbonation alone. Maruyama et al. [9] gave advanced dehydration as the reason for this, and mentioned calcium peroxide octahydrate, produced as a result of radiolysis, as a possible pathway to forming vaterite. In our study, we can rule out the action of calcium peroxide octahydrate as it is unstable [21, 48] and declines quickly once the irradiation is halted, meaning the contribution in our sequential irradiation-then-carbonation study is negligible. Figure 9 shows that the samples exposed to heat treatment also 
demonstrated a change in the dominant calcium carbonate polymorph, but to a lesser extent compared to the irradiated sample, as shown by the maximum calcite: vaterite of 0.82 for the heat treated samples compared to 1.16 for the irradiated samples. This confirms that thermal dehydration is partially responsible for the change in calcium carbonate polymorph switch, however, the difference in the XRD results indicates that there must be an additional process occurring in the irradiated samples. Since Figure 4 shows the mass loss for both the irradiated and heat-treated samples $(3.71 \pm 0.47 \%$ and $3.30 \pm 0.11 \%$ respectively) after the treatment stage were within error, this additional process cannot simply be due to water radiolysis leading to further dehydration.

Auroy et al. [28] have shown that the different carbonate polymorphs have different hydrated cement phase precursors: calcite was formed from portlandite, aragonite was formed from ettringite and vaterite was formed from C-S-H. Conversion of the precursor phases prior to carbonation is ruled out by considering the sections of the XRD heatmaps in Figure 8 that are well below the carbonation depth. Portlandite, C-S-H and quartz are all present in the uncarbonated region. Another potential mechanism is the thermodynamically driven vaterite to calcite transformation [25], which could be accelerated by heat and/ or gamma irradiation.Rodriguez-Blanco et al. [25] used synthesised calcium carbonates in an aqueous solution and observed spherical indentations in the cubic calcite, which correlated to the nucleation $\underline{\text { sites on the spherical vaterite particles. As shown in Figure 10, the calcite }}$ particle did not feature a spherical indentation indicitative of a vaterite to calcite transformation.Consequently, the calcite phase appear to be forming 
from the pre-cursor phases directly, rather than the transforming through different carbonation polymorphs. Figure 10 provides one more piece of information showing a somewhat imperfect morphology, rather than the perfectly cubic morphology of calcite, which is discussed in the next section.

\subsection{Evidence of Pore Water Chemistry Influencing Polymorph Formation}

The reason for vaterite forming in the control samples can also be explored, with our results concurring with the findings of Auroy et al. [28], which showed vaterite to be the dominant calcium carbonate polymorph in fly-ash blended samples. Figure 11 shows a reduction of $52.14 \mathrm{pm} 12.50 \%$ and $81.60 \pm 6.63 \%$ for $\mathrm{Na}$ and $\mathrm{K}$ respectively elemental concentration at the carbonated edge of the material compared to the middle (non-carbonated) section. This implies that in the carbonated region of the cement samples $\mathrm{Na}$ and $\mathrm{K}$ are incorporated into an in-soluble solid phase, whereas in the non-carbonated area they are dissolved in the pore water.

Hofmann et al. [49] showed that $\mathrm{Na}^{+}$and $\mathrm{K}^{+}$ions adsorbing to the calcite surface destabilised the polymorph while Ishikawa and Ichikuni [50] calculated that $\mathrm{Na}$ could sit in a calcite lattice as an interstitial atom alongside a Ca-vacancy. Other research utilising synthesised calcium carbonates has shown that the incorporation of ions such as $\mathrm{S}$ or $\mathrm{Mg}$ into the calcite lattice destabilises the polymorph $[23,24]$, with the inclusion of S leading to an increase in the c-axis [23]. A smaller change in the c-axis was observed for aragonite and there was no change for vaterite [23], meaning that these polymorphs are not destabilised by the inclusion of $\mathrm{S}$ and so are more stable than S-containing calcite. We consider that a similar phenomenon may also be occurring for $\mathrm{Na}$ and $\mathrm{K}$; interaction of these ions into the carbonate 
lattice would explain the decrease in $\mathrm{Na}$ and $\mathrm{K}$ concentration in the leachate at the carbonated edge. Na sitting within the carbonate lattice would result in some Ca being removed from the calcium carbonate lattice, which would explain the increased $\mathrm{Ca}$ content at the edge. Consequently, these authors propose that incorporation of $\mathrm{Na}$ and $\mathrm{K}$ with the calcium carbonate lattice is destabilising calcite and causing vaterite to become the dominant polymorph in the control sample.

As shown by Figure 11, Mg isn't being leached in the non-carbonated area and only a very small amount is observed in the carbonated edge. Consequently, it appears that $\mathrm{Mg}$ is unlikely to be taking part in the solution chemistry. There was a notable increase in the concentration of $\mathrm{S}$ in the leachate from the carbonated edge of the sample, indicating that ettringite carbonation has occurred $[28,38,39]$.

The reason for the polymorph switch with gamma irradiation and or heating can also be explored. There is more carbonate formed in the irradiated and heat treated samples compared to the control sample, as demonstrated by Figure 6 and the mean carbonation ingresses provided in Table 2 showing on average twice as much carbonatioon ingress for the heat treated and carbonated samples. Given that the uptake of $\mathrm{Na}$ and $\mathrm{K}$ is similar across all three treatment methods, this suggests that the concentration of $\mathrm{Na}$ and $\mathrm{K}$ in the carbonate phase is lower in the irradiated and heat treated samples. The lower concentration of $\mathrm{Na}$ and $\mathrm{K}$ in carbonate phases for the irradiated and heat treated samples cause less destabilisation and so make the formation of a more stable polymorph likely; this is why we also see calcite in these samples. To the best of our knowledge a study has not been performed 
that would determine the competing effects of these ions on calcite morphology. In future work spectroscopic techniques such as x-ray photoelectron spectroscopy (XPS) or nuclear magnetic resonance (NMR) can be used to examine the structure of the carbonate phases.

The observed calcite crystal in Figure 10 was imperfect, supporting our hypothesis that elements are substituting in and altering the crystal structure. Consequently, we believe that chemical processes, which are influenced by the composition of the pore water, are also having an effect on the carbonation product formation. As discussed previously, $\mathrm{Na}$ and $\mathrm{K}$ cations are less concentrated in the carbonation phase for the irradiated and heated samples, resulting in less destabilisation to the calcite phase, which explains why this phase is observed. A dissolution of $\mathrm{S}$ is also observed in the centre of the samples for both the irradiated and heated samples, however, the effect of this is currently unknown. Literature has shown that amount of $\mathrm{S}$ in solution alters the carbonation polymorph, with vaterite becoming more dominant at higher S concentration $[51,25]$. We are unable to tell if this is occurring in our sample, given the other complex mechanisms that are happening simultaneously.

\section{Conclusions}

We have shown that the carbonation depth of samples increased when the samples were pre-treated with either gamma irradiation or heat exposure prior to accelerated carbonation. This is relevant to the nuclear industry, as is shows increased carbonation depth is not limited to systems where the radiation and carbonation occur simultaneously and could occur in systems 
that experience a radiation field and then are exposed to the atmosphere, like a nuclear waste storage facility maybe. Vaterite was observed as the dominant carbonation phase in the control sample. We propose the vaterite formation is due to the pore water chemistry, in-particular the $\mathrm{Na}$ and $\mathrm{K}$ ions being either incorporated into the calcite lattice or adsorbing onto the surface, de-stabilisng the calcite polymorph. A switch in the carbonation phase from vaterite to calcite was observed with gamma irradiation or heating prior to carbonation, with gamma irradiation having more substantial effect than heating alone. The polymorph formed in carbonation is important for the nuclear industry to know as the different molar volumes affect the porosity differently and could lead to a different timescale for the self termination of the carbonate reaction. The use of a sequential process infers that the calcium peroxide octahydrate does not play a significant part in the carbonation or the carbonation product switch due to it being highly unstable.

A definite mechanism behind the carbonation product switch remains unclear, however, currently our results concur with the literature that advanced dehydration being a factor. These authors also propose that chemical processes are also influencing the switch in carbonation phase, as demonstrated by the pore water data. We propose that the gamma irradiation is accelerating these processes, rather than creating a separate mechanism, resulting in the larger calcite:vaterite ratio.

\section{Acknowledgements}

This work is funded through an EPSRC iCase award through the Nuclear

Decommissioning Authority, sponsored by Sellafield ltd. We acknowledge the 
support of The University of Manchester's Dalton Cumbrian Facility (DCF), a partner in the National Nuclear User Facility, the EPSRC UK National Ion Beam Centre and the Henry Royce Institute. We recognise Dr. R. Edge and Dr. G. Glodan for their assistance during the irradiation and SEM work respectively. The authors would like to thank Mr E. Butcher and Mr G. Cann of the National Nuclear Laboratory for their supervision, provided on behalf of Sellafield Ltd.

The author(s) acknowledge the use of the School of Materials X-ray Diffraction Suite at the University of Manchester and for the technical support, advice and assistance provided by Gary Harrison and Dr. J. Warren. The authors would like to thank Dr. Helmut Glünder for providing the code used to analyse the phenolpthalein images. The authors would like to thank Mr Paul Lythgoe for running the ICP-AES samples at the Manchester Analytical Geochemistry Unit, part of the Williamson Research Centre. 


\section{References}

\section{References}

[1] D. Naus, Primer on Durability of Nuclear Power Plant Reinforced Concrete Structures - A Review of Pertinent Factors Primer on Durability of Nuclear Power Plant Reinforced Concrete Structures - A Review of Pertinent Factors, Technical Report, Oak Ridge National Laboratory, 2006.

[2] W. Ashraf, Carbonation of cement-based materials: Challenges and opportunities, Construction and Building Materials 120 (2016) 558-570.

[3] B. Šavija, M. Luković, Carbonation of cement paste: Understanding, challenges, and opportunities, Construction and Building Materials 117 (2016) 285-301.

[4] S. Hussain, D. Bhunia, S. B. Singh, Comparative study of accelerated carbonation of plain cement and fly-ash concrete, Journal of Building Engineering 10 (2017) 26-31.

[5] H. Taylor, Cement Chemistry, Thomas Telford Publishing, second edition, 1997.

[6] C. D. Atiş, Accelerated carbonation and testing of concrete made with fly ash, Construction and Building Materials 17 (2003) 147-152.

[7] M. Stefanoni, U. Angst, B. Elsener, Corrosion rate of carbon steel in carbonated concrete - A critical review, Cement and Concrete Research 103 (2018) 35-48. 
[8] S. Ahmad, Reinforcement corrosion in concrete structures, its monitoring and service life prediction - A review, Cement and Concrete Composites 25 (2003) 459-471.

[9] I. Maruyama, S. Ishikawa, J. Yasukouchi, S. Sawada, R. Kurihara, Impact of gamma-ray irradiation on hardened white portland cement pastes exposed to atmosphere, Cement and Concrete Research 108 (2018) 59-71.

[10] F. Vodák, V. Vydra, K. Trtík, O. Kapičková, Effect of gamma irradiation on properties of hardened cement paste, Materials and Structures 44 (2011) 101-107.

[11] G. Bar-Nes, A. Katz, Y. Peled, Y. Zeiri, The combined effect of radiation and carbonation on the immobilization of $\mathrm{Sr}$ and $\mathrm{Cs}$ ions in cementitious pastes, Materials and Structures 41 (2008) 1563-1570.

[12] H. Hilsdorf, J. Kropp, H. Koch, The Effects of Nuclear Radiation on Materials, Technical Report 4, Inst1tute for Bu1ld1ng Materials, University of Karlsruhe, 1959.

[13] F. Vodák, K. Trtík, V. Sopko, O. Kapičková, P. Demo, Effect of $\gamma$ irradiation on strength of concrete for nuclear-safety structures, Cement and Concrete Research 35 (2005) 1447-1451.

[14] P. Soo, L. Milian, The effect of gamma radiation on the strength of Portland cement mortars, Journal of materials science letters 20 (2001) $1345-1348$. 
[15] N. Mobasher, S. a. Bernal, H. Kinoshita, C. a. Sharrad, J. L. Provis, Gamma irradiation resistance of an early age slag-blended cement matrix for nuclear waste encapsulation, Journal of Materials Research (2015) $1-9$.

[16] B. Craeye, G. De Schutter, C. Vuye, I. Gerardy, Cement-waste interactions: Hardening self-compacting mortar exposed to gamma radiation, Progress in Nuclear Energy 83 (2015) 212-219.

[17] E. Tajuelo Rodriguez, W. A. Hunnicutt, P. Mondal, Y. Le Pape, Examination of gamma-irradiated calcium silicate hydrates. Part I: Chemicalstructural properties, Journal of the American Ceramic Society 103 (2020) 558-568.

[18] F. Chupin, A. Dannoux-Papin, Y. Ngono Ravache, J. B. d'Espinose de Lacaillerie, Water content and porosity effect on hydrogen radiolytic yields of geopolymers, Journal of Nuclear Materials 494 (2017) 138146.

[19] S. Le Caër, L. Dezerald, K. Boukari, M. Lainé, S. Taupin, R. M. Kavanagh, C. S. Johnston, E. Foy, T. Charpentier, K. J. Krakowiak, R. J. Pellenq, F. J. Ulm, G. A. Tribello, J. Kohanoff, A. Saúl, Production of $\mathrm{H} 2$ by water radiolysis in cement paste under electron irradiation: A joint experimental and theoretical study, Cement and Concrete Research 100 (2017) 110-118.

[20] O. Kontani, S. Sawada, I. Maruyama, M. Takizawa, O. Sato, Evaluation of Irradiation Effects on Concrete Structure - Gamma Ray Irradiation 
Tests on Cement Paste -, in: Proceedings of the ASME 2013 Power Conference, pp. 1-8.

[21] P. Bouniol, E. Bjergbakke, A comprehensive model to describe radiolytic processes in cement medium, Journal of Nuclear Materials 372 (2008) 1-15.

[22] M. Ni, B. D. Ratner, J. Wiley, Differentiating calcium carbonate polymorphs by surface analysis techniques - an XPS and TOF-SIMS study, Surface \& Interface Analysis 40 (2008) 1356-1361.

[23] P. Bots, L. G. Benning, R. E. Rickaby, S. Shaw, The role of SO4 in the switch from calcite to aragonite seas, Geology 39 (2011) 331-334.

[24] J. W. Morse, Q. Wang, M. Y. Tsio, Influences of temperature and Mg:Ca ratio on CaCO 3 precipitates from seawater, Geology 25 (1997) $85-87$.

[25] J. D. Rodriguez-Blanco, S. Shaw, L. G. Benning, The kinetics and mechanisms of amorphous calcium carbonate (ACC) crystallization to calcite, via vaterite., Nanoscale 3 (2011) 265-271.

[26] J. D. Rodriguez-Blanco, S. Shaw, P. Bots, T. Roncal-Herrero, L. G. Benning, The role of $\mathrm{pH}$ and $\mathrm{Mg}$ on the stability and crystallization of amorphous calcium carbonate, Journal of Alloys and Compounds 536 (2012) S477-S479.

[27] M. Castellote, L. Fernandez, C. Andrade, C. Alonso, Chemical changes and phase analysis of OPC pastes carbonated at different $\mathrm{CO} 2$ concentrations, Materials and Structures 42 (2009) 515-525. 
[28] M. Auroy, S. Poyet, P. Le Bescop, J. M. Torrenti, T. Charpentier, M. Moskura, X. Bourbon, Comparison between natural and accelerated carbonation (3\% CO2): Impact on mineralogy, microstructure, water retention and cracking, Cement and Concrete Research 109 (2018) 6480.

[29] Y.-H. Hsiao, B. Wang, E. Callagon, L. Plante, I. Pignatelli, N. M. A. Krishnan, The effect of irradiation on the atomic structure and chemical durability of calcite and dolomite, npj Materials Degradation (2019) 19.

[30] B. Pomaro, A review on radiation damage in concrete for nuclear facilities: From experiments to modeling, Modelling and Simulation in Engineering (2016) 1-10.

[31] K. Field, I. Remec, Y. Le Pape, Radiation effects in concrete for nuclear power plants - Part I: Quantification of radiation exposure and radiation effects, Nuclear Engineering and Design 282 (2015) 126-143.

[32] BS EN 197-1:2011, Cement. Composition, specifications and conformity criteria for common cements, Standard, British Standards Institution, 2011.

[33] BS EN 450-2:2005, Fly ash for concrete. Conformity evaluation, Standard, British Standards Institution, 2005.

[34] L. Leay, W. Bower, G. Horne, P. Wady, A. Baidak, M. Pottinger, M. Nancekievill, A. D. Smith, S. Watson, P. R. Green, B. Lennox, J. A. 
Laverne, S. M. Pimblott, Development of irradiation capabilities to address the challenges of the nuclear industry, Nuclear Instruments and Methods in Physics Research, Section B: Beam Interactions with Materials and Atoms 343 (2015) 62-69.

[35] W. Hansen, Drying Shrinkage Mechanisms in Portland Cement Paste, Journal of the American Ceramic Society 70 (1987) 323-328.

[36] I. Maruyama, Origin of drying shrinkage of hardened cement paste: Hydration pressure, Journal of Advanced Concrete Technology 8 (2010) $187-200$.

[37] L. De Ceukelaire, D. Van Nieuwenburg, Accelerated carbonation of a blast-furnace cement concrete, Cement and Concrete Research 23 (1993) $442-452$.

[38] D. Zhang, D. Xu, X. Cheng, W. Chen, Carbonation resistance of sulphoaluminate cement-based high performance concrete, Journal Wuhan University of Technology, Materials Science Edition 24 (2009) $663-666$.

[39] L. Fernández-Carrasco, D. Torréns-Martín, S. Martínez-Ramírez, Carbonation of ternary building cementing materials, Cement and Concrete Composites 34 (2012) 1180-1186.

[40] M. Thommes, K. Kaneko, A. V. Neimark, J. P. Olivier, F. RodriguezReinoso, J. Rouquerol, K. S. Sing, Physisorption of gases, with special reference to the evaluation of surface area and pore size distribution 
(IUPAC Technical Report), Pure and Applied Chemistry 87 (2015) 1051-1069.

[41] S. Le Caër, P. Rotureau, F. Brunet, T. Charpentier, G. Blain, J. P. Renault, J. C. Mialocq, Radiolysis of confined water: Hydrogen production at a high dose rate, ChemPhysChem 6 (2005) 2585-2596.

[42] P. Rotureau, J. P. Renault, B. Lebeau, J. Patarin, J. C. Mialocq, Radiolysis of confined water: Molecular hydrogen formation, ChemPhysChem 6 (2005) 1316-1323.

[43] N. G. Petrik, A. B. Alexandrov, A. I. Vall, Interracial energy transfer during gamma radiolysis of water on the surface of $\mathrm{ZrO} 2$ and some other oxides, Journal of Physical Chemistry B 105 (2001) 5935-5944.

[44] E. Craven, F. Hasanain, M. Winters, Minimizing material damage using low temperature irradiation, Radiation Physics and Chemistry 81 (2012) $1254-1258$.

[45] S. Shaffer, K. Yang, J. Vargas, M. A. Di Prima, W. Voit, On reducing anisotropy in $3 \mathrm{D}$ printed polymers via ionizing radiation, Polymer 55 (2014) 5969-5979.

[46] P. Wady, A. Wasilewski, L. Brock, R. Edge, A. Baidak, C. McBride, L. Leay, A. Griffiths, C. Vallés, Effect of ionising radiation on the mechanical and structural properties of 3D printed plastics, Additive Manufacturing 31 (2020) 100907.

[47] L. L. Snead, Y. Katoh, T. Koyanagi, K. Terrani, Stored energy release 
in neutron irradiated silicon carbide, Journal of Nuclear Materials 514 (2019) 181-188.

[48] P. Bouniol, Disappearance of Oxygen in Concrete Under Irradiation: the Role of Peroxides in Radiolysis, Cement and concrete research 28 (1998) 1669-1681.

[49] S. Hofmann, K. Voïtchovsky, P. Spijker, M. Schmidt, T. Stumpf, Visualising the molecular alteration of the calcite (104) - Water interface by sodium nitrate, Scientific Reports 6 (2016) 1-11.

[50] M. Ishikawa, M. Ichikuni, A Model of Crystal Defects in Calcite by Sodium and Potassium Uptake, Bulletin of the Chemical Society of Japan 59 (1986) 3809-3814.

[51] I. C. Mayorga, J. M. Astilleros, L. Fernández-Díaz, Precipitation of caco 3 polymorphs from aqueous solutions: The role of ph and sulphate groups, Minerals 9 (2019) 1-16. 